\title{
Pengaruh LKS Berbasis Problem Solving untuk Meningkatkan Keterampilan Berpikir Kritis Siswa
}

\author{
Eka Novita Sari*, Ratu Betta Rudibyani, Emmawaty Sofya \\ Program Studi Pendidikan Kimia, Universitas Lampung, Indonesia \\ *Corresponding email: ekanovitasariA2@gmail.com
}

\begin{abstract}
The Effect of Problem Solving Based Worksheet to Improve Students Critical Thinking Skill. This research aims to describe the effect of using problem solving based worksheet to improve students critical thinking skills. The research design used is non equivalence pretest-posttest control group design. The sample of this research were students in class X MIPA 2 as control class and X MIPA 3 as experiment class, which were selected by cluster random sampling. The research data consisting of the values of pretest, posttest and n-Gain. The effect of worksheet to improve students critical thinking skill is calculated using the effect test formula. The results of data analysis and calculations show that worksheets applied to the experimental class have a greater effect than the control class. Therefor, it can be concluded that problem solving based worksheet has been taken effect to improve students critical thinking skills.
\end{abstract}

Keyword: problem solving based student worksheet, critical thinking, electrolyte and non-elektrolyte solution.

\begin{abstract}
Abstrak: Pengaruh LKS Berbasis Problem Solving untuk Meningkatkan Keterampilan Berpikir Kritis Siswa. Penelitian ini bertujuan mendeskripsikan pengaruh LKS berbasis problem solving untuk meningkatkan keterampilan berpikir kritis siswa. Desain penelitian yang digunakan adalah non eqivalence pretes-postes control group design. Sampel penelitian ini adalah siswa kelas X MIPA 2 sebagai kelas kontrol dan X MIPA 3 sebagai kelas eksperimen, yang dipilih secara cluster random sampling. Data penelitian terdiri dari nilai pretes, postes dan $n$-Gain. Besarnya pengaruh LKS untuk meningkatkan keterampilan berpikir kritis siswa dihitung menggunakan rumus uji pengaruh (effect size). Hasil analisis data dan perhitungan menunjukkan bahwa LKS yang diterapkan pada kelas eksperimen memiliki pengaruh yang lebih besar dibandingkan kelas kontrol. Dengan demikian, dapat disimpulkan bahwa LKS berbasis problem solving berpengaruh untuk meningkatkan keterampilan berpikir kritis siswa.
\end{abstract}

Kata kunci: LKS berbasis problem solving, keterampilan berpikir kritis, larutan elektrolit dan non elektrolit. 


\section{PENDAHULUAN}

Seperti yang kita ketahui, abad 21 telah memasuki era baru bernama Era Revolusi Industri 4.0 yang ditan-dai dengan percepatan dibidang ilmu pengetahuan dan teknologi informa-si. Era baru ini memberikan dampak yang cukup luas dalam berbagai bidang kehidupan, salah satunya da-lam bidang pendidikan. Pendidikan semakin penting dikarenakan pendi-dikan sebagai usaha untuk memper-siapkan peserta didik memiliki taraf kesejahtraan hidup yang lebih baik. Oleh karena itu, diperlukan sistem pembelajaran yang menyelaraskan tujuan pembelajaran dengan tuntutan zaman agar pembelajaran menjadi lebih bermakna (Maemunah, 2018; Sudarisman, 2015; Wijaya, 2016).

Sejalan dengan hal ini, Kemen-dikbud merumuskan bahwa paradig-ma pembelajaran abad 21 menginte-grasikan pada keterampilan $4 \mathrm{C}$ yaitu keteram-pilan berpikir kritis (Critical thinking), kreatif (Creative), kolabo-rasi dan komunikasi (Collaboration and Communication). Bila kita cer-mati, keterampilan berpikir kritis (Critical thinking) merupakan salah satu modal utama bagi anak untuk menjadi manusia mandiri dalam kehidupan masa depan yang kompe-titif, sehingga keterampilan ini sangat perlu dilatihkan kepada para siswa saat proses pembelajaran berlangsung (Widiowati, 2009).

Keterampilan berpikir krtis merupakan berpikir rasional (masuk akal) dan refleksi berfokus pada keyakinan dan keputusan yang akan dilakukan (Ennis, 2011). Salah satu keterampilan berpikir kritis yang dipilih untuk dilatihkan kepada siswa saat pembelajaran berlangsung ada-lah bertanya dan menjawab pertanyaan, mempertimbangkan sumber dapat dipercaya atau tidak, mengobservasi dan membuat laporan hasil observasi, membuat keputusan dan menyelesaikan masalah tentang apa yang harus dipercayai atau dilakukan (Ennis, 1989; Arifin, 2017). Masalah yang diberikan kepa-da siwa hendaknya diperoleh berda-sarkan fenomena-fenomena dalam kehidupan sehari-hari atau fenomen alam. Cabang dari Ilmu Pengetahuan Alam (IPA) yang berkembang berda-sarkan fenomena alam dan diajarkan di jenjang SMA/ SMK adalah mata pelajaran kimia (Fadiawati, 2011).

Pelajaran kimia yang umumnya berupa konsep, hukum dan teori serta pengaplikasian dari kehidupan seha-ri-hari terkadang sangat sulit dipaha-mi oleh siswa. Hal ini mengakibat-kan siswa cenderung kurang mampu memberikan alasan terhadap penye-lesaian suatu permasalahan, tidak mempu mengembangkan cara baru dalam menyelesaikan masalah, tidak dapat memberikan jawaban yang bervariasi serta kurang mampu me-ngembangkan gagasan yang ada (Busnawir, 2015). Padahal pembela-jaran pada abad 21 idelanya men-dorong siswa mencari tahu dari berbagai sumber bukan diberi tahu, mengarahkan siswa untuk mampu merumuskan masalah bukan hanya menyelesaikan masalah dan menga-rahkan siswa untuk melatih berfikir analitis bukan berfikir mekanistis (Wijaya, 2016).

Hasil pengamatan saat melaku-kan observasi pendahuluan di SMA Negeri 13 Bandar Lampung, di peroleh hasil bahwa saat proses pem-belajaran kimia berlangsung guru sudah mengarahkan siswa untuk memperoleh pengetahuan dan kosep materi yang diajarkan, akan tetapi masih kurang melatihkan keteram-pilan berpikir kritis kepada siswa. Hal ini dibuktikan, hanya beberapa siswa yang mampu mengembang-kan keterampilan berpikir kritis pada sub bertanya dan menjawab per-tanyaan serta memberikan penjelasan sederhana.

Berdasarkan kondisi tersebut, salah satu alternatif yang diharapkan dapat digunakan untuk melatih siswa meningkatkan keterampilan berpikir kritis adalah 
dengan adanya media ajar berupa LKS berbasis problem solving. Menurut Lestari (2013) menyatakan LKS merupakan salah satu media pembelajaran yang mem-bantu siswa memahami materi yang diajarkan dan mengkonstruk penge-tahuannaya sendiri, sehingga selama kegiatan proses belajar mengajar ber-langsung kelas menjadi aktif dan pembelajaran berlangsung secara efektif dan efisien. Prianto dan Harnoko (1997) menambahkan, sela-in mengaktifkan siswa dalam proses pembelajaran LKS juga membantu siswa memperoleh catatan tentang materi yang dipelajari melalui kegi-atan belajar, membantu siswa untuk menambah informasi tentang konsep yang dipelajari melalui kegiatan belajar secara sistematis dan melatih siswa untuk menemukan dan mengembangkan konsep yang diajar-kan.

LKS berbasis problem solving merupakan salah satu contoh LKS dimana penyusunannya mengguna-kan model problem solving sehingga didalamnya berisi langkah-langkan yang mengadopsi dari model pro-blem solving dan dirancang untuk meningkatkan keterampilan berpikir kritis siswa. Adapun langkah-lang-kah dalam pembelajaran problem solving menurut Sudjana (2009) yaitu (1) Adanya masalah yang jelas untuk dipecahkan. Masalah ini harus tumbuh sesuai dengan taraf kemam-puannya, (2) Mencari data atau kete-rangan yang dapat digunakan untuk memecahkan masalah tersebut. Mi-salnya, dengan jalan membaca buku-buku, meneliti, bertanya dan berdiskusi, (3) Menetapkan jawaban se-mentara dari masalah tersebut. Duga-an jawaban ini tentu saja didasarkan kepada data yang telah diperoleh, (4) Menguji kebenaran jawaban semen-tara dari masalah tersebut. Dalam langkah ini siswa harus berusaha memecahkan masalah sehingga betuk-betul yakin bahwa jawaban tersebut benar-benar cocok. Apakah sesuai dengan jawaban sementara atau sama sekali tidak sesuai. Untuk menguji kebenaran jawaban ini tentu saja diperlukan metode-metode lainnya seperti demonstrasi dan tugas diskusi dan (5) Menarik kesimpulan. Artinya siswa harus sampai kepada kesim-pulan terakhir tentang jawaban dari masalah yang ada.

Penelitian yang mendukung tentang LKS berbasis problem solving adalah hasil penelitian dari Lambertus (2014) yang menyebutkan bahwa terdapat peningkatan kemam-puan belajar siswa pada pembe-lajaran dengan model pemecahan masalah dibandingkan dengan pem-belajaran konvensional, dan dapat meningkatkan keaktifan siswa men-capai persentase rata-rata sebesar $82,32 \%$. Penelitian serupa tentang pengaruh LKS berbasis pemecahan masalah atau problem solving dapat meningkatkan keterampilan berpikir kritis siswa dengan persentase "se-dang" dilakukan oleh (1)Hidayat (2014) pada materi fluida dinamis, (2)Nisa (2015) pada materi peran manusia dalam pengelolaan lingku-ngan dan (3)Malahayati (2017) pada materi keanekaragaman hayati.

Berdasarkan uraian tersebut, maka telah dilakukan penelitian yang bertujuan mendeskripsikan pengaruh LKS berbasis problem solving untuk meningkatkan keterampilan berpikir kritis siswa.

\section{METODE}

Desain yang digunakan dalam penelitian ini adalah Non Equiva-lence PretestPosttest Control Group Design menurut Fraenkel (2012). Pengambilan sampel dilakukan dengan teknik cluster random sampling. Dari seluruh siswa kelas X MIPA SMA Negeri 13 Bandar Lampung tahun pelajaran 2018/2019 yang tersebar kedalam 6 kelas diperoleh dua kelas penelitian, yaitu kelas X MIPA 3 sebagai kelas eksperimen dan kelas X MIPA 2 sebagai kelas kontrol. 
Prosedur dalam penelitian ini terdiri dari tahap pendahuluan yaitu melakukan izin penelitian, melaku-kan observasi, menentukan sampel penelitian. Tahap pelaksanaan pene-litian yaitu tahap persiapan dan penelitian. Tahap penelitian akhir yaitu analisis data, pembahasan dan kesimpulan.

Instrumen tes yang digunakan dalam penelitian ini terdiri dari LKS berbasis problem solving dan soal pretes-postes keterampilan berpikir kritis. Soal pretes-postes keteram-pilan berpikir kritis terdiri dari 5 soal uraian. Soal pretes dan postes yang akan digunakan penelitian diujikan pada 31 siswa di kelas XI MIPA 2 untuk melihat apakah soal yang digunakan valid dan reliabel. Analsis uji validitas dan reliabilitas dihitung menggunakan aplikasi IBM SPSS statistic 23. Soal dika-takan valid apabila diperoleh $\mathrm{r}_{\text {hitung }}>\mathrm{r}_{\text {tabel }}$ dengan taraf signifikan sebesar 5\% (Arikunto, 2006). Reliabilitas ditentukan menggunakan Cronbach's Alpha. Dengan kriteria derajat reliabilitas $\left(\mathrm{r}_{11}\right)$ menurut Guilford yang ditunjukkan pada Tabel berikut ini.

Tabel 1. Kriteria derajat reliabilitas

\begin{tabular}{ll}
\hline $\begin{array}{l}\text { Derajat reliabilitas } \\
\left(\mathbf{r}_{11}\right)\end{array}$ & Kriteria \\
\hline $0.80<\mathrm{r}_{11} \leq 1.00$ & Sangat tinggi \\
$0.60<\mathrm{r}_{11} \leq 0.80$ & Tinggi \\
$0.40<\mathrm{r}_{11} \leq 0.60$ & Sedang \\
$0.20<\mathrm{r}_{11} \leq 0.40$ & Rendah \\
$0.00<\mathrm{r}_{11} \leq 0.20$ & $\begin{array}{l}\text { Tidak } \\
\text { releiabel }\end{array}$ \\
\hline
\end{tabular}

Terdapat dua jenis data yang digunakan dalam penelitian ini yaitu data primer dan data pendukung. Data primer terdiri dari nilai pretes dan postes siswa. Data primer Diana-lisis secara kuantitatif menggunakan aplikasi microsoft excel untuk mencari nilai $n$-Gain, nilai $n$-Gain dihitung dengan menggunakan rumus sebagai berikut (Hake,1998):

$$
n-G a i n=\frac{\text { wilai postes }-\$ 6 \text { nilai pretes }}{100-\$ 6 \text { nillai pretes }}
$$

Selain menganalisis data yang dipe-roleh setelah penelitian, dilakukan juga pengujian hipotesis data dengan aplikasi IBM SPSS statistic 23 untuk uji normalitas, uji homogenitas, uji t', uji paired sample t-test dan uji pengaruh (effect size).

Suatu data dikatakan berasal dari populasi terdistribusi normal dan homogen jika memenuhi asumsi yaitu, hasil pada kolom Kolmogorov-Smirnov nilai sig. > 0.05 . Uji taksen digunakan untuk mengetahui ada tidaknya perbedaan keterampilan berpikir kritis siswa pada kedua kelas yang dilihat dari nilai $n$-Gain masing-masing kelas, dengan asumsi terima $\mathrm{H}_{1}$ apabila nilai sig.(2-tailed) < 0.05 , adapun hipotesis penelitian sebagai berikut:

$\mathrm{H}_{0}$ : Tidak terdapat perbedaan kete-rampilan berpikir kritis pada kedua kelas.

$\mathrm{H}_{1}$ : Terdapat perbedaan keteram-pilan berpikir kritis pada kedua kelas.

Uji paired sample t-test digunakan untuk memperoleh nilai derajat kebe-basan (df) dan $\mathrm{t}$ hitung dari uji perbe-dan nilai pretes-postes masing-masing kelas, sehingga dapat diten- 
tukan besarnya pengaruh dari LKS yang diterapkan pada masing-masing kelas dengan menggunaka rumus uji effect size sebagai berikut (Jahjouh, 2014).

$$
\mu^{2}=\frac{t^{2}}{t^{2}+d f}
$$

Keterangan:

$\mu=$ effect size

$\mathrm{t}=\mathrm{t}$ hitung dari uji- $t$

$d f=$ derajat kebebasan.

Kriteria efek pengaruh yang disaji-kan pada tabel berikut ini (Dincer, 2015).

Tabel 2. Kriteria efek pengaruh

\begin{tabular}{ll}
\hline Efek pengaruh & $\begin{array}{l}\text { Kriteria } \\
\text { efek }\end{array}$ \\
\hline$\mu \leq 0.15$ & Sangat kecil \\
$0.15<\mu \leq 0.40$ & Kecil \\
$0.40<\mu \leq 0.75$ & Sedang \\
$0.75<\mu \leq 1.10$ & Besar \\
$\mu>1.10$ & Sangat besar \\
\hline
\end{tabular}

Data pendukung dalam pene-litian ini, terdiri dari angket respon siswa dan lembar keterlaksanaan pembelajaran menggunakan LKS berbasis prolem solving. Data pendukung dianalisis secara kuantitatif dengan cara menghitung presentase ketercapaian untuk setiap aspek pengamatan dengan rumus sebagai berikut (Sudjana, 2005):

$$
\% J i=\frac{\sum J i}{N} \times 100 \%
$$

Keterangan:

$\% \mathrm{Ji}=$ Presentase ketercapaian dari skor ideal untuk setiap aspek pengamatan pada pertemuan ke-i

$\Sigma \mathrm{Ji}=$ Jumlah skor setiap aspek pengamatan yang diberikan oleh observer atau pengamat pada pertemuan ke-i

$\mathrm{N}=$ Skor maksimal (skor ideal)

Setelah menghitung persentase keter-capaian untuk setiap aspek penga-matan, kemudian menafsirkan data dengan tafsiran harga persentase ketercapaian menurut Ratumanan seperti pada tabel berikut ini:

Tabel 3. Kriteria persentase ketercapaian

\begin{tabular}{cl}
\hline \multicolumn{1}{c}{ Persentase } & \multicolumn{1}{c}{ Kriteria } \\
\hline $80.1 \%-100.0 \%$ & Sangat tinggi \\
$60.1 \%-80.0 \%$ & Tinggi \\
$40.1 \%-60.0 \%$ & Sedang \\
$20.1 \%-40.0 \%$ & Rendah \\
$0.0 \%-20.0 \%$ & Sangat rendah \\
\hline (Ratumana dalam Sunyono, 2012)
\end{tabular}




\section{HASIL DAN PEMBAHASAN}

Instrument tes berupa soal pre-tes-postes keterampilan berpikir krtitis yang digunakan dalam pene-litian ini valid dan reliabel, dimana pada hasil analisis diperoleh nilai $r_{\text {hitung }}>r_{\text {tabel }}$ seperti yang ditunjukkan pada Tabel 3 dengan derajat relia-bilitas sebesar 0.819 yang berkriteria sangat tinggi.

Tabel 3. Hasil uji validitas soal pre-tes-postes keterampilan ber-pikir kritis

\begin{tabular}{cccc}
\hline $\begin{array}{c}\text { Butir } \\
\text { Soal }\end{array}$ & $\mathbf{r}_{\text {hitung }}$ & $\mathbf{r}_{\text {tabel }}$ & $\begin{array}{c}\text { Kriteria } \\
\text { soal }\end{array}$ \\
\hline 1 & 0.478 & 0.367 & Valid \\
2 & 0.521 & 0.367 & Valid \\
\hline 3 & 0.495 & 0.367 & Valid \\
$4(\mathrm{a})$ & 0.452 & 0.367 & Valid \\
$4(\mathrm{~b})$ & 0.396 & 0.367 & Valid \\
5 & 1 & 0.367 & Valid \\
\hline
\end{tabular}

Hasil analisis data primer menujukkan bahwa terdapat per-bedaan rata-rata nilai pretes-postes dan $n$-Gain di kelas kontrol dan eksperimen seperti yang disajikan pada Gambar 1 dan Gambar 2.

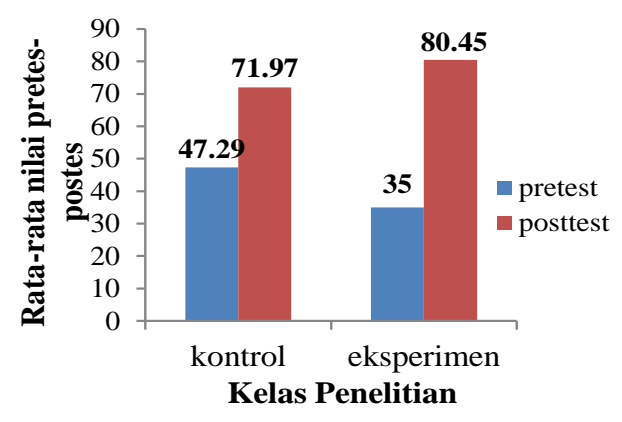

Gambar 1. Grafik perbandingan rata-rata nilai pretes-postes keterampilan berpikir kritis siswa kelas kontrol dan kelas eksperimen

Gambar 1 menunjukkan bahwa rata-rata nilai keterampilan berpikir kritis awal siswa (skor pretes) di kelas kontrol lebih baik dibandingkan dengan kelas eksperimen. Kedua kelas sama-sama mengalami pening-katan rata-rata nilai keterampilan berpikir kritis setelah diberikan per-lakuan (skor postes) namun, pening-katan yang cukup signifikan terlihat pada kelas eksperimen. Hal ini dikarenakan perbedaan perlakuan yang diberikan, dimana pada kelas kontrol diterapkan LKS konvensio-nal sedangkan pada kelas eksperimen diterapkan LKS berbasis problem solving.

Untuk mengetahui seberapa besar peningkatan keterampilan berpikir kritis yang terjadi pada masing-masing kelas penelitian, maka dapat dilihat melalui rata-rata nilai $n$ Gain yang disajikan pada gambar berikut ini. 


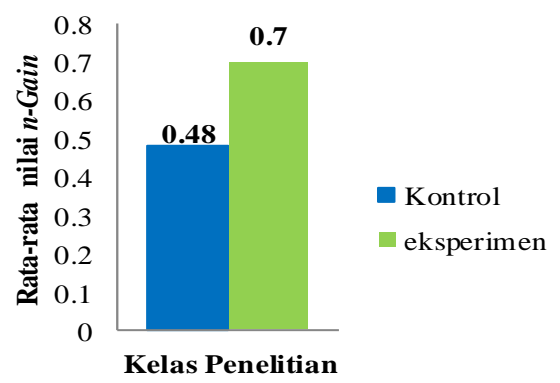

Gambar 2. Grafik perbandingan rata-rata nilai $n$-Gain keteram-pilan berpikir kritis siswa

Gambar 2 menunjukkan bahwa rata-rata nilai $n$-Gain kelas eksperimen lebih besar dibandingkan kelas kon-trol artinya, peningkatan keteram-pilan berpikir kritis pada kelas ekspe-rimen lebih tinggi dibandingkan kelas kontrol. Tingginya peningkatan keterampilan berpikit kritis pada ke-las eksperimen menunjukkan bahwa indikatorindikator keterampilan ber-pikir kritis yang dilatihkan kepada siswa dengan menggunakan media ajar berupa LKS berbasis problem solving menyebabkan keterampilan berpikir kritis siswa meningkat jauh lebih baik dari keterampilan berpikir kritis awal. Pada kelas kontrol yang memiliki keterampilan berpikir kritis awal lebih baik mengalami pening-katan keterampilan berpikir kritis yang tidak terlalu tinggi dikarenakan LKS konvensional yang diberikan tidak terdapat indikator-indikator keterampilan berpikir kritis seperti yang dilatihkan di kelas eksperimen. Hal tersebut relevan dengan pene-litian yang telah dilakukan oleh Pramesti (2017) yang menyatakan bahwa LKS berbasis problem solving baik untuk digunakan.

Adapun uraian dari masing-masing tahapan pada LKS berbasis problem solving yaitu pada tahap pertama siswa dihadapkan pada su-atu masalah yang harus diselesaikan oleh siswa. Pada tahap ini, siswa diharapkan akan terstimulus untuk mendefinisikan atau merumuskan pertanyaan dan merumuskan solusi alternatif mengenai masalah yang dihadapi. Pada tahap kedua yakni mencari data atau keterangan yang dapat digunakan untuk memecahkan masalah yang sedang dihadapi sehingga siswa dapat mengemukakan solusi alternative terhadap permasa-lahan yang dihadapi. Kemudian, pada tahap ketiga yakni menetapkan jawaban sementara berdasarkan latar belakang fakta-fakta dan penerapan konsep yang dapat diterima. Pada tahap keempat yakni menguji kebenaran dari jawaban sementara, siswa akan terpacu untuk melakukan eksperimen dalam rangka meme-cahkan masalah berdasarkan fakta dalam percobaan. Dengan melaku-kan percobaan ini, siswa diharapkan dapat mempertimbangkan prosedur yang tepat saat merancang percobaan dan melaporkan hasil observasi serta mempertanggung jawabkan hasil observasi setelah melakukan perco-baan. Pada tahap kelima yakni menarik kesimpulan, siswa diharap-kan dapat mengkontruksi argument yang diperoleh setelah melakukan argument sehingga diperoleh suatu kesimpulan.

Langkah selanjutnya yaitu melakukan pengujian hipotesis. Hasil pengujian hipotesis normalitas untuk masing-masing data primer menun-jukkan bahwa terdapat dua data yang tidak memenuhi asumsi bahwa sampel berasal dari populasi terdistribusi normal atau memiliki nilai sig. $<0.05$ pada kolom kolmogorov-smirnov yaitu, data postes kelas kontrol dan data pretes kelas ekspe-rimen, sedangkan untuk keempat data 
lainnya memenuhi asumsi terdistribusi normal seperti yang disajikan pada tabel berikut ini.

Tabel 4. Hasil uji normalitas

\begin{tabular}{llll}
\hline \multirow{2}{*}{ Kelas } & \multicolumn{3}{c}{ Nilai sig. } \\
\cline { 2 - 4 } & $\begin{array}{l}\text { Pre- } \\
\text { tes }\end{array}$ & $\begin{array}{l}\text { Pos- } \\
\text { tes }\end{array}$ & $\begin{array}{l}\text { n- } \\
\text { Gain }\end{array}$ \\
\hline Kontrol & 0.132 & 0.046 & 0.200 \\
\hline $\begin{array}{l}\text { Eksperi- } \\
\text { men }\end{array}$ & 0.000 & 0.152 & 0.191 \\
\hline
\end{tabular}

Pengujian hipotesis uji homogenitas menunjukkan bahwa data primer yang diperoleh tidak memenuhi asumsi sampel berasal dari populasi yang homogen atau memiliki nilai sig. $<0.05$ pada kolom kolmogorov-smirnov yang disajikan pada Tebel 5. Artinya, keterampilan berpikir kritis siswa pada kelas eksperimen dan kelas kontrol berva-riasi, ada yang memiliki keteram-pilan berpikir kritis tinggi, sedang dan rendah.

Tabel 5. Hasil uji homogenitas

\begin{tabular}{cc}
\hline Data & Nilai sig. \\
\hline Pretes & 0.04 \\
Postes & 0.00 \\
$n$-Gain & 0.00 \\
\hline
\end{tabular}

Berdasarkan dua pengujian hi-potesis sebelumnya, untuk data $n$-Gain kedua kelas terdistribusi secara normal akan tetapi tidak homogen oleh karena itu, dilakukanlah pengujian hipotesis data $n$-Gain menggunakan uji t' untuk menge-tahui apakah terdapat perbedaan keterampilan berpikir kritis pada kedua kelas. Hasil uji t' menun-jukkan bahwa nilai sig. $\left(2\right.$-tailed) $<0.05$ artinya terima asumsi $\mathrm{H}_{1}$ yaitu terdapat perbedaan keterampilan berpikir kritis pada kedua kelas. Artinya, setiap perlakuan yang diterapkan pada masing-masing kelas penelitian memiliki pengaruh yang berbeda beda terhadap keterampilan berpikir kritis siswa. Adapun, hasil uji t' disajikan pada tabel 6.

Tabel 6. Hasil uji t'

\begin{tabular}{lcccc}
\hline Kelas & Mean & Df & $\mathbf{t}_{\text {hitung }}$ & $\begin{array}{c}\text { Sig.(2- } \\
\text { tailed) }\end{array}$ \\
\hline Kontrol & 0.482 & 60 & -4.465 & 0.000 \\
Eksperimen & 0.700 & & & \\
\hline
\end{tabular}

Besar pengaruh LKS yang diterapkan pada masing-masing kelas dihitung menggunakan rumus uji effect size dimana nilai df dan $t_{\text {hitung }}$ diperoleh dari hasil uji paired sample t-test, adapun hasil uji dan perhi-tungan dapat dilihat pada tabel berikut.

Tabel 7. Hasil uji effect size

\begin{tabular}{lllll}
\hline Data & Mean & $\mathbf{d f}$ & $\mathbf{t}_{\text {hitung }}$ & $\boldsymbol{\mu}$ \\
\hline Kelas kontrol & & & \\
Pretes & 47.290 & 30 & -11.326 & 0.81
\end{tabular}


Postes $\quad 71.968$

Kelas eksperimen

Pre-tes $\quad 35.000$

Pos-tes $\quad 80.452 \quad 30 \quad-29.473 \quad 0.98$

Hasil perhitungan effect size terlihat bahwa baik LKS konven-sional maupun LKS berbais problem solving sama-sama memiliki kriteria pengaruh "besar" dimana, LKS kon-vensional yang diterapkan di kelas kontrol memberikan pengaruh se-besar 0.81 artinya, 81\% keterampilan berpikir kritis siswa dipengaruhi oleh LKS konvensional, sedangkan LKS berbasis problem solving yang diterapkan di kelas eksperimen memberikan pengaruh sebesar 0.98 artinya, 98\% keterampilan berpikir kritis siswa dipengaruhi oleh LKS berbasis problem solving.

Hasil analisis data pendukung yang berupa lembar observasi keter-laksanaan LKS berbasis problem solving dan perhitungan angket res-pon positif siswa menunjukkan rata-rata persentase dengan kriteria yang tinggi. Adapun hasil perhitungan analisis lembar keterlaksanaan LKS berbasis problem solving disajikan pada tabel berikut ini.

Tabel 8. Hasil perhitungan lembar observasi keterlaksanaan LKS berbasis problem solving

\begin{tabular}{|c|c|c|}
\hline $\begin{array}{c}\text { Pertemu } \\
\text { an } \\
\text { ke- }\end{array}$ & $\begin{array}{c}\text { Aspek } \\
\text { Pengamat } \\
\text { an }\end{array}$ & $\begin{array}{c}\text { Persentase } \\
\text { Ketercapaian } \\
(\%)\end{array}$ \\
\hline \multirow{4}{*}{1} & Sintak & 80.00 \\
\hline & $\begin{array}{l}\text { Sistem } \\
\text { Sosial }\end{array}$ & 75.00 \\
\hline & $\begin{array}{l}\text { Perilaku } \\
\text { Guru }\end{array}$ & 75.00 \\
\hline & $\begin{array}{l}\text { Rata-Rata } \\
\text { Pertemuan } \\
1\end{array}$ & 76.67 \\
\hline \multirow{4}{*}{2} & Sintak & 82.50 \\
\hline & $\begin{array}{l}\text { Sistem } \\
\text { Sosial }\end{array}$ & 75.00 \\
\hline & $\begin{array}{l}\text { Perilaku } \\
\text { Guru }\end{array}$ & 81.25 \\
\hline & $\begin{array}{l}\text { Rata-Rata } \\
\text { Pertemuan } \\
2\end{array}$ & 79.58 \\
\hline \multirow{4}{*}{3} & Sintak & 87.50 \\
\hline & $\begin{array}{l}\text { Sistem } \\
\text { Sosial }\end{array}$ & 81.25 \\
\hline & $\begin{array}{l}\text { Perilaku } \\
\text { Guru }\end{array}$ & 81.25 \\
\hline & $\begin{array}{l}\text { Rata-Rata } \\
\text { Pertemuan } \\
\mathbf{3}\end{array}$ & 83.33 \\
\hline \multicolumn{2}{|c|}{ Rata-Rata } & 79.86 \\
\hline
\end{tabular}




\begin{tabular}{ccc}
\hline $\begin{array}{c}\text { Pertemu } \\
\text { an } \\
\text { ke- }\end{array}$ & $\begin{array}{c}\text { Aspek } \\
\text { Pengamat } \\
\text { an }\end{array}$ & $\begin{array}{c}\text { Persentase } \\
\text { Ketercapaian } \\
(\%)\end{array}$ \\
\hline \multicolumn{2}{c}{ Keterlaksanaan } \\
\hline
\end{tabular}

Tabel 8 menunjukkan bahwa rata-rata keterlaksanaan pembela-jaran menggunakan LKS berbasis problem solving di kelas kontrol semakin meningkat di setiap pertemuan. Artinya, LKS ini dapat dipahami dan diterima dengan baik oleh siswa.

Hal ini didukung juga dengan hasil perhitungan respon positif siswa yang menunjukkan rata-rata persentase sebesar $92.74 \%$ dan memiliki tafisiran persentase keter-capaian sangat tinggi yang dapat dilihat pada tabel dibawah ini.

Tabel 9. Hasil perhitungan skor angket respon siswa terhadap pelaksanaan pembelajaran menggunakan LKS berbasis problem solving

\begin{tabular}{|c|c|c|c|}
\hline No. & As & pek & $\begin{array}{c}\text { Persentase } \\
\text { Respon } \\
\text { Siswa }(\%) \\
\end{array}$ \\
\hline \multirow{5}{*}{1.} & \multirow{5}{*}{$\begin{array}{l}\text { Persaan } \\
\text { senang } \\
\text { terhadap }\end{array}$} & $\begin{array}{l}\text { Materi } \\
\text { pembelaja } \\
\text { ran }\end{array}$ & 93.55 \\
\hline & & $\begin{array}{l}\text { Lembar } \\
\text { Kegiatan } \\
\text { Siswa } \\
\end{array}$ & 90.32 \\
\hline & & $\begin{array}{l}\text { Suasana } \\
\text { belajar } \\
\text { dikelas }\end{array}$ & 93.55 \\
\hline & & $\begin{array}{l}\text { Cara guru } \\
\text { mengajar }\end{array}$ & 100.00 \\
\hline & & $\begin{array}{l}\text { Cara guru } \\
\text { merespon }\end{array}$ & 100.00 \\
\hline \multirow{5}{*}{2.} & \multirow{5}{*}{$\begin{array}{l}\text { Pendapat } \\
\text { siswa } \\
\text { tentang } \\
\text { kebaruan } \\
\text { terhadap }\end{array}$} & $\begin{array}{l}\text { Materi } \\
\text { pembelajar } \\
\text { an }\end{array}$ & 90.32 \\
\hline & & $\begin{array}{l}\text { Lembar } \\
\text { Kegiatan } \\
\text { Siswa } \\
\end{array}$ & 93.55 \\
\hline & & $\begin{array}{l}\text { Suasana } \\
\text { belajar } \\
\text { dikelas }\end{array}$ & 87.10 \\
\hline & & $\begin{array}{l}\text { Cara guru } \\
\text { mengajar }\end{array}$ & 96.77 \\
\hline & & $\begin{array}{l}\text { Cara guru } \\
\text { merespon }\end{array}$ & 93.55 \\
\hline 3. & \multicolumn{2}{|c|}{$\begin{array}{l}\text { Minat siswa terhadap } \\
\text { pembelajaran }\end{array}$} & 100.00 \\
\hline 4. & $\begin{array}{l}\text { Pemaham } \\
\text { an kemu- }\end{array}$ & $\begin{array}{l}\text { Pemaham } \\
\text { an bahasa }\end{array}$ & 87.10 \\
\hline
\end{tabular}




\begin{tabular}{|c|c|c|c|}
\hline No. & \multicolumn{2}{|c|}{ Aspek } & $\begin{array}{c}\text { Persentase } \\
\text { Respon } \\
\text { Siswa }(\%) \\
\end{array}$ \\
\hline & \multirow[t]{4}{*}{$\begin{array}{l}\text { dahan dan } \\
\text { ketertarik } \\
\text { an siswa } \\
\text { terhadap } \\
\text { LKS }\end{array}$} & $\begin{array}{l}\text { Ketertarik } \\
\text { an pada } \\
\text { penampila } \\
\text { n LKS }\end{array}$ & 90.32 \\
\hline & & $\begin{array}{l}\text { Pemahama } \\
\mathrm{n} \text { isi mate } \\
\text { ri }\end{array}$ & 87.10 \\
\hline & & $\begin{array}{l}\text { Kemenari } \\
\text { kan waca } \\
\text { na }\end{array}$ & 87.10 \\
\hline & & $\begin{array}{l}\text { Kemudah } \\
\text { an mempe } \\
\text { lajari mate } \\
\text { ri }\end{array}$ & 93.55 \\
\hline \multicolumn{3}{|c|}{$\begin{array}{l}\text { Rata-rata persentase } \\
\text { respon siswa }\end{array}$} & 92.74 \\
\hline
\end{tabular}

Dari hasil analisis data primer dan data pendukung yang telah dijabarkan menunjukan bahwa, penelitian ini relevan dengan penelitian yang telah dilakukan oleh Nisa (2015) dan Malahayati (2017) pada materi biologi yang me-nyatakan bahwa LKS berbasis problem solving dapat meningkatkan keterampilan berpikir kritis siswa. Pada penelitian ini juga diperoleh hasil bahwa LKS berbasis problem solving memiliki pengaruh yang besar terhadap keterampilan berpikir kritis siswa.

\section{KESIMPULAN}

LKS berbasis problem solving berpengaruh untuk meningkatkan keterampilan berpikir kritis siswa dengan kriteria efek besar. LKS yang diterapkan pada kelas eksperimen memiliki pengaruh yang lebih besar dibandingkan kelas kontrol. LKS berbasis problem solving berpengaruh untuk meningkatkan keterampilan berpikir kritis siswa.

\section{REFERENSI}

Arifin, Z. 2017. Mengembangkan Instrument Pengukur Critical Thinking Skill Siswa pada Pembelajaran Matematika Abad 21. Jurnal Theorems, 1(2) : 92-100.

Arikunto, S. 2006. Prosedur Pene-litian : Suatu Pendekatan Praktik. Rineka Cipta: Jakarta.

Busnawir. 2015 . Kajian Keteram-pilan Berpikir Kreatif Matema-tika Melalui Kegiatan Lesson Study. Jurnal Pendidikan Matematika. 5(2) : 159-161.

Dincer, S. 2015. Effect of Computer Assited Learning on Student Achievement in Turkey: a Meta Analysis. Journal of Turkish Science Education, 12(1), 99-118.

Ennis, R. H. 1989. Critical Thingking and Subject Specificity Clarification and Needed Research. Journal Education, 18(3) : 4-10.

Ennis, R. H. 2011. The Nature of Critical Thinking: An Outline of Critical Thinking Dispositions And Abilities. University of Illinois : Chicago. 
Fadiawati, N. 2011. Perkembangan Konsepsi Pembelajaran Ten-tang Struktur Atom Dari SMA Hingga Perguruan Tinggi. (Disertasi). Perpustakaan Uni-versitas Pendidikan Indonesia.

Fraenkel, J. R., N. E. Wallen, \& H. H. Hyun. 2012. How to Design and Evaluate Research in Education Eigth Edition. McGrow-Hill : New York.

Hake, R. R. 1998. Interactive-Engagement Versus Traditional Methods, A six ThousandStudent Survey of Mechanics Test Data For Introductory Physics Coures. American Journal of Physics, 66(1): 67-74.

Hidayat, T. 2014. Pengaruh Penggunaan Lembar Kerja Siswa (LKS)Berbasis Problem Solving Polya Pada Konsep Fluida Dinamis Terhadap Kemampuan Menganalisis Siswa. (Skripsi). Universitas Islam Negeri Syarif Hidaya-tullah. Jakarta.

Jahjouh, Y. M. A. 2014. The Effectiveness of Blended E-Learning Forumin Planning for Science Instruction. Juornal of Turkish Science Education, 11(4):3-16.

Lambertus., Bey, A., Anggo, M., Fahinu., Sudia, M., dan Kadir. 2014. Developing Skills Resolution Mathematical Primary School Students. International Journal of Education and Research, 2(10): 601- 614.

Lestari, I. 2013. Pengembangan Bahan Ajar Berbasis Kompe-tensi. Akademia Permata : Padang.

Maemunah. 2018. Kebijakan Pendidi-kan Pada Era Revolusi Industri. Prosiding Seminar Nasional Lembaga Penelitian dan Pendidikan (LPP) Man-dala, Universitas Muhammadiyah Mataram, 29 September.

Malahayati, E. N. 2017. Pengaruh Lembar Kerja Siswa (LKS) Berbasis Creative Problem Solving (CPS) Pada Materi Keanekaragaman Hayati Untuk Meningkatkan Kemampuan Berpikir Krtitis Dan Hasil Belajar Siswa Kelas X SMA Negeri 4 Blitar. Kontruktivisme, 9(2) : 14-158.

Nisa, D. K. 2015. Pengaruh Penggunaan LKS Berbasis Masalah Terhadap Keterampilan Berpikir Kritis Siswa. Jurnal Bioterdidik Wahana Ekspresi Ilmiah, 3(5).

Pramesti, E.T. 2017. Pengembangan LKS Larutan Elektrolit dan Non Elektrolit Berbasis Problem Solving. Jurnal Pendidikan dan Pembelajaran Kimia, 6(1).

Prianto dan Harnoko. 1997. Perangkat Pembelajaran. Depdikbud : Jakarta.

Sudarisman, S. 2015. Memahami Hakikat dan Karakteristik Pembelajaran Biologi dalam Upaya Menjawab Tantangan Abad 21 Serta Optimalisasi Implementasi Kurikulum 2013. Jurnal Flora, 2(1) : 29-35.

Sudjana, N. 2009. Dasar-dasar Proses Belajar Mengajar. Sinar Baru Algensindo: Bandung.

Sudjana. 2005. Metode Statistika. Tarsito: Bandung.

Sunyono. 2012. Buku Model Pembelajaran Berbasis Multipel Representasi (Model SiMaYang). Anugrah Utama Raharja: Bandar Lampung.

Widowati, A. 2009. Pengembangan Critical Thinking Melalui Penerapan Model PBL (Problem Based learning) Dalam Pembelajaran Sains. Prosiding Seminar Nasional Penelitian Pendidkan dan Penerapan MIPA, Universitas Negeri Yogyakarta, $16 \mathrm{Mei}$.

Wijaya, E. Y., Sudjamat, D. A., \& Nyoto, A. 2016. Transformasi Pendidikan Abad 21 Sebagai Tuntutan Pengembangan Sumber Daya Manusia Di Era Global. Prosiding Seminar Nasional Pendidikan Matema-tika, Volume 1 tahun 2016, Universitas Negeri Malang. 